\title{
ANALISIS KUAT GESER TANAH CLAY SHALE YANG TERENDAM DAN TIDAK TERENDAM DENGAN UNCONFINED COMPRESSION TEST
}

\author{
Hans Tantra', dan Aniek Prihatiningsih ${ }^{2}$ \\ ${ }^{1}$ Program Studi Sarjana Teknik Sipil, Universitas Tarumanagara, Jl. Letjen S. Parman No.1 Jakarta \\ Email: hanstantra88@gmail.com \\ ${ }^{2}$ Program Studi Sarjana Teknik Sipil, Universitas Tarumanagara, Jl. Letjen S. Parman No.1 Jakarta \\ Email: aniekprihatiningsih@gmail.com
}

\begin{abstract}
ABSTRAK
Tanah di Indonesia terdiri dari berbagai macam jenis dan karakteristik yang berbeda-beda. Sehingga di setiap proses konstruksi, kita perlu mengidentifikasi terlebih dahulu jenis dan karakteristik tanah apa yang menjadi dasar konstruksi tersebut dibangun. Salah satu jenis tanah yang ada di Indonesia yang sering menyebabkan masalah selama pembangunan, yaitu tanah clay shale. Tanah clay shale memiliki karakteristik mudah mengalami pelapukan tanah jika terus menerus terekspos dengan udara, pelapukan tanah dapat mengakibatkan penurunan kuat geser tanah yang dapat menyebabkan terjadinya longsor di daerah konstruksi bangunan. Melalui tes unconfined compression test kita dapat memperoleh nilai kuat tekan dan kuat geser. Dalam penelitian ini, lokasi sampel yang akan di uji berasal dari Jl.Babakan Sirkuit Tangkil, Citereup, Bogor, Indonesia. Pengetasan unconfined compression test akan dilakukan pada laboratorium tanah Universitas Tarumanagara. Untuk sampel yang akan diuji terdiri dari dua kondisi sampel dengan keadaaan berbeda. Sampel akan diuji dalam kondisi rendam dan tidak rendam dengan masing-masing durasi sampel di rendam dan tidak rendam selama 0 minggu, 1 minggu, 3 minggu, 5 minggu, dan 7 minggu. Hasil penelitian menunjukkan nilai kuat tekan terbesar pada sampel yang tidak di rendam berada pada durasi 5 minggu pendiaman sebesar $1133.2275 \mathrm{kN} / \mathrm{m}^{2}$ dan mulai menurun pada sampel dengan durasi 7 minggu. Untuk sampel dengan kondisi terendam, kuat tekan terbesar berada pada sampel 1 minggu perendaman dengan nilai sebesar $11.635 \mathrm{kN} / \mathrm{m}^{2}$ dan nilai kuat tekan mulai menurun pada sampel dengan durasi 3 minggu rendaman. Nilai kohesi pada percobaan ini berbanding lurus dengan nilai kuat tekan sehingga untuk sampel tidak rendam, nilai kohesi terbesar berada pada kondisi pendiaman 5 minggu dan untuk sampel rendam nilai kohesi terbesar berada pada kondisi perendaman 1 minggu..
\end{abstract}

Kata kunci: clay shale, kuat tekan, kuat geser, unconfined compression test

\section{PENDAHULUAN}

Dalam setiap proses konstruksi kita sering menemukan adanya proses penggalian yang membentuk sebuah lereng. Lereng seringkali mengalami ketidakstabilan sehingga dapat meyebabkan terjadinya longsor. Tanah di Indonesia terdiri dari berbagai jenis tanah yang memiliki karakteristik berbeda-beda, salah satunya jenis tanah clay shale. Tanah clay shale memiliki karakteristik yang sering menimbulkan masalah pada saat proses konstruksi dikarenakan clay shale dapat mengalami pelapukan jika terekspose dengan udara dan air. Pelapukan yang terjadi dapat menyebabkan penurunan kuat geser pada daerah tanah tersebut berada sehingga dapat menimbulkan potensi longsor jika tanah clay shale berada pada lereng suatu konstruksi. Tujuan dari pengujian unconfined compression test adalah mencari nilai kuat tekan dan nilai kuat geser dari tanah clay shale.

Untuk pengujian unconfined compression test akan dilakukan dalam dua kondisi yaitu, kondisi sampel saat terendam dan kondisi sampel saat tidak terendam. Durasi perendaman dan tidak rendam akan berlangsung mulai dari 0 minggu, 1 minggu, 3 minggu, 5 minggu, dan 7 minggu. Pengujian unconfined compression test akan dilakukan dengan standar ASTM D-2166. Hasil yang akan ditinjau adalah nilai dari kuat tekan, nilai kohesi dan nilai sudut geser dalam yang diperoleh melalui korelasi nilai kohesi terhadap N-SPT.

\section{TINJAUAN PUSTAKA}

\section{Studi Pustaka}

Langkah awal untuk memulai penelitian ini yaitu, memperoleh definisi, fungsi, tujuan serta langkah-langkah kerja dari pengujian karakteristik tanah yang mencakup uji specific gravity, atterberg limits, grain size, compaction, 
unconfined compression test, dan perhitungan sudut geser dalam. Seluruh standar pengujian yang digunakan dalam penelitian ini menggunakan ASTM (American Society fot Testing and Materials).

\section{Unconfined Compression Test (UCT)}

Uji UCT dilakukan dengan menggunakan standar ASTM D-2116. Uji UCT dilakukan untuk mengukur nilai kuat tekan $\left(\mathrm{q}_{\mathrm{u}}\right)$, dan nilai kohesi $(\mathrm{C})$. Untuk perhitungannya dapat dinyatakan sebagai berikut:

$$
\sigma=\frac{\mathrm{P}}{\mathrm{A}}
$$

Dimana $\sigma=$ Tegangan Normal, $\mathrm{P}=$ Beban yang diberikan, dan $\mathrm{A}=$ Luas rata-rata

$$
\mathrm{C}=\frac{\sigma}{2}
$$

Dimana $\mathrm{C}=$ Kohesi, dan $\sigma=$ Tegangan Normal

\section{Sudut Geser Dalam $(\varnothing)$}

Untuk menghitung nilai sudut geser dalam diperlukan nilai kohesi dari hasil percobaan, Nilai kohesi akan dikorelasikan terhadap nilai N-SPT lalu akan dicari berapa nilai sudut geser dalam. Untuk mencari korelasi antara nilai kohesi terhadap nilai N-SPT menggunakan rumus empiris dalam laporan Updating Bearing Capacity - SPT Graphs yang dinyatakan oleh NAVFAC pada tahun 1982:

$$
C=0.038 N
$$

Setelah memperoleh nilai N-SPT digunakan interpolasi linear terhadap nilai sudut geser yang terdapat dalam tabel 1

\begin{tabular}{|c|c|c|c|}
\hline $\begin{array}{c}\text { SPT N } \\
(\text { Blows } / 0.3 \mathrm{~m})\end{array}$ & Soil Packing & $\begin{array}{c}\text { Relative } \\
\text { Density } \\
(\%)\end{array}$ & $\begin{array}{c}\text { Friction Angle } \\
\left({ }^{0}\right)\end{array}$ \\
\hline$<4$ & Very Loose & $<20$ & $<30$ \\
\hline 4 to 10 & Loose & 20 to 40 & 30 to 35 \\
\hline 10 to 30 & Compact & 40 to 60 & 35 to 40 \\
\hline 30 to 50 & Dense & 60 to 80 & 40 to 45 \\
\hline$>50$ & Very Dense & $>80$ & $>45$ \\
\hline
\end{tabular}
yang ditemukan oleh Meyerhoff pada tahun 1956 dimana tabelnya dapat dilampirkan sebagai berikut:

Tabel 1. Perbandingan Antar Nilai $\mathrm{N}_{\mathrm{Spt}}$ dengan Nilai Sudut Geser Dalam 


\section{METODOLOGI PENELITIAN}

Secara umum tahapan penelitian dapat dilihat pada diagram alir pada gambar 1 .

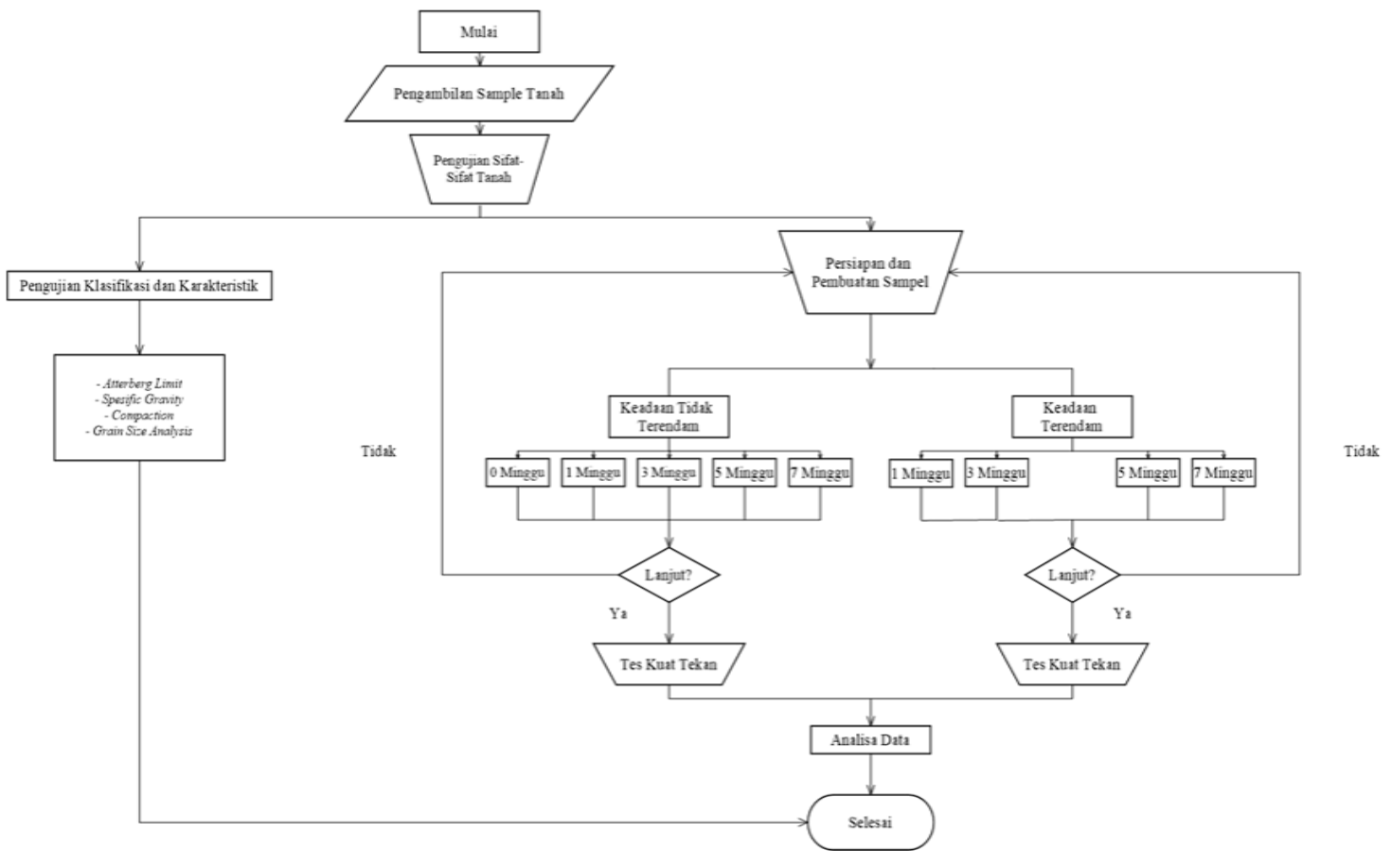

Gambar 1. Diagram Alir Percobaan

\section{Pengambilan Sampel Tanah}

Lokasi pengambilan sampel untuk percobaan yang dilakukan berada di Jl. Bababkan Sirkui Tangkil, Citeureup, Bogor, Jawab Barat, Indonesia. Tanah yang diambil berada di kedalaman 6.00 - 10 meter di bawah lapisan permukaan tanah. Sampel tanah yang diuji bersifat terganggu (disturbed).

\section{Pengujian Awal Sifat Karakteristik Tanah}

Untuk mengetahui karakteristik dari tanah yang akan diuji, diperlukan beberapa penujian yang mencakup:

1. Index Properties (ASTM D-2216),

2. Specific Gravity Test (ASTM D-854),

3. Atterberg Limits (ASTM D-4318),

4. Grain Size (ASTM D-422),

5. Compaction (ASTM D-698).

Uji Compaction dilakukan agar dapat mengetahui kadar air optimum dari sampel tanah yang diuji.

\section{Pengujian Unconfined Compression Test (UCT)}

Sampel terendam dan sampel tidak rendam akan diuji dengan unconfined compression test dengan standar ASTM D-2116. Pengujian akan menggunakan mesin CBR dengan merek Teclock buatan Jepang dengan kapasitas $6000 \mathrm{lbf}$ atau setara dengan 2721.55 kgf. Proses penekanan sampel dilakukan hingga pembacaan pada load dial menurun atau hingga dicapai regangan sebesar 15\% berdasarkan ASTM D-2116

\section{ANALISIS DAN PEMBAHASAN}

Untuk mengetahui karakteristik tanah yang diuji, dilakukan pengujian specific gravity, atterberg limits, grain size analysis dan compaction. Berikut hasil dari pengujian karakterstik yang telah dilakukan. 


\section{Hasil Uji Nilai Specific Gravity}

Berikut hasil uji dari specifc gravity yang dapat dilihat pada Tabel 2.

Tabel 2. Hasil Uji nilai Gravitasi Spesifik

\begin{tabular}{ccc}
\hline Keterangan & Sampel 1 & Sampel 2 \\
\hline Gs $\left(\mathrm{Tx}=28^{\circ} \mathrm{C}\right)$ & 2.56 & 2.65 \\
\hline Gs $\left(20^{\circ} \mathrm{C}\right)$ & 2.56 & 2.64 \\
\hline Rata-rata Gs & & 2.60 \\
\end{tabular}

\section{Hasil Uji Nilai Atterberg Limits}

Berdasarkan hasil uji atterbeg limits yang dilakukan diperoleh bahwa tanah yang diuji ada tanah lanau organik dengan plastisitas rendah / low plasticity organic silt (ML or OL). Hasil pengujian dapat dilihat pada Table 3.

Tabel 3. Nilai Liquid Limit (LL), Plastic Limit (PL), dan Plasticity Index (PI)

\begin{tabular}{cccc}
\hline Keterangan & Sampel 1 & Sampel 2 & Rata - rata \\
\hline Liquid Limit (\%) & 36.489 & 34.664 & 35.5765 \\
\hline Plastic Limit (\%) & 25.72 & 26.91 & 26.315 \\
\hline Plasticity Index (\%) & 10.77 & 7.76 & 9.265 \\
\hline
\end{tabular}

\section{Hasil Uji Grain Size}

Berikut hasil uji dari Grain Size yang dapat dilihat pada Tabel 4.

Tabel 4. Persentase Distribusi Komposisi Butiran Tanah

\begin{tabular}{cccc}
\hline Jenis Tanah & Sampel 1 & Sampel 2 & Rata-rata \\
\hline Persentase Gravel & $1.26 \%$ & $4.58 \%$ & $2.92 \%$ \\
\hline Persentase Sand & $5.40 \%$ & $5.64 \%$ & $5.52 \%$ \\
\hline Persentase Silt & $74.50 \%$ & $71.66 \%$ & $73.08 \%$ \\
\hline Persentase Clay & $18.84 \%$ & $18.12 \%$ & $18.48 \%$ \\
\hline
\end{tabular}

\section{Hasil Uji Compaction}

Dari pengujian compaction diperoleh nilai kadar air optimum sebesar $14.95 \%$ dan kepadatan kering tanah adalah $17.16 \mathrm{kN} / \mathrm{m}^{3}$. 


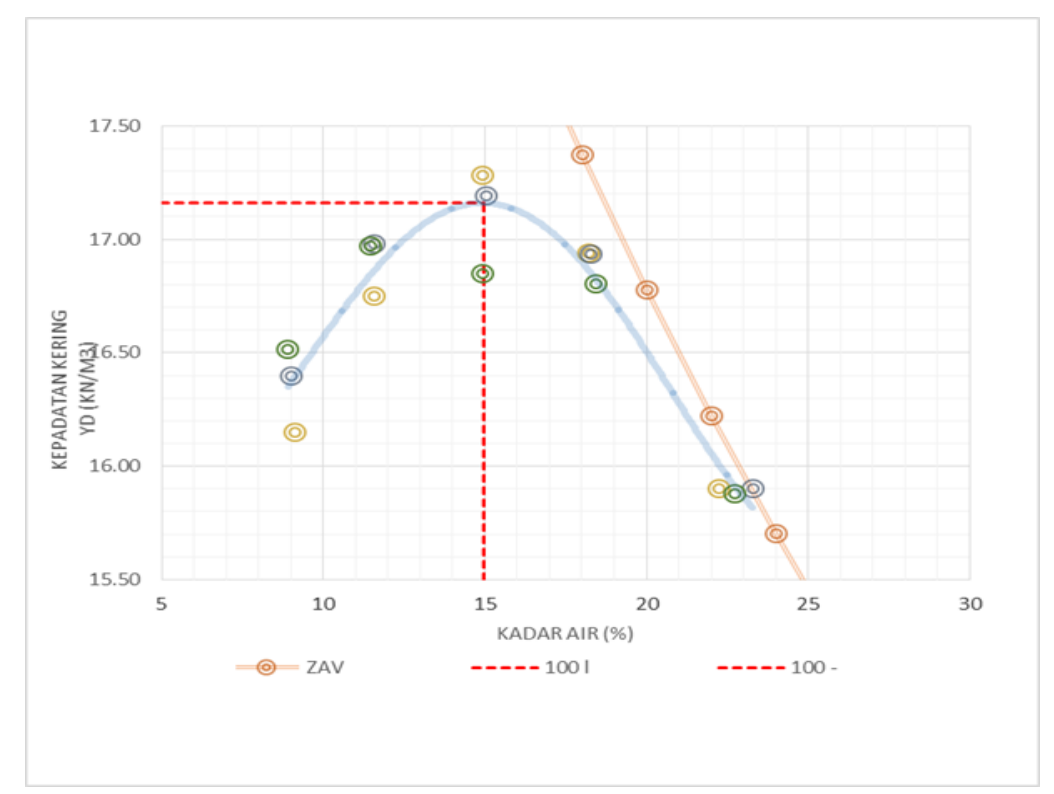

Gambar 2. Kadar Air Optimum dari Uji Compaction

\section{Hasil Uji Unconfined Compression Test (UCT)}

Setelah melakukan pengujian dan perhitungan dari unconfined compression test, diperoleh data-data nilai kuat tekan sampel tidak rendam akan disajikan dalam Tabel 5 dan untuk nilai kuat tekan sampel terendam akan disajikan dalam Tabel 6.

Tabel 5. Nilai Kuat Tekan Sampel Tidak Rendam

\begin{tabular}{cccccc}
\hline $\begin{array}{c}\text { Sampel } \\
\text { UCT }\end{array}$ & $\begin{array}{c}\text { 0 Minggu } \\
\mathrm{q}_{\mathrm{u}}\left(\mathrm{kN} / \mathrm{m}^{2}\right)\end{array}$ & $\begin{array}{c}\text { 1 Minggu } \\
\mathrm{q}_{\mathrm{u}}\left(\mathrm{kN} / \mathrm{m}^{2}\right)\end{array}$ & $\begin{array}{c}3 \text { Minggu } \\
\mathrm{q}_{\mathrm{u}}\left(\mathrm{kN} / \mathrm{m}^{2}\right)\end{array}$ & $\begin{array}{c}5 \text { Minggu } \\
\mathrm{q}_{\mathrm{u}}\left(\mathrm{kN} / \mathrm{m}^{2}\right)\end{array}$ & $\begin{array}{c}7 \mathrm{Ming} \mathrm{qu} \\
\mathrm{q}_{\mathrm{u}}\left(\mathrm{kN} / \mathrm{m}^{2}\right)\end{array}$ \\
\hline Sampel 1 & 312.08 & 633.9 & 1152.62 & 1193.86 & 1164.13 \\
\hline Sampel 2 & 265.75 & 506.95 & 544.89 & 1192.6 & 935.07 \\
\hline Sampel 3 & - & - & - & 952.9 & 898.44 \\
\hline Sampel 4 & - & - & - & 1193.55 & 993.18 \\
\hline Avg & 288.915 & 570.425 & 848.755 & 1133.2275 & 997.705 \\
\hline
\end{tabular}

Tabel 6. Nilai Kuat Tekan Sampel Rendam

\begin{tabular}{ccccc}
\hline $\begin{array}{c}\text { Sampel } \\
\text { UCT }\end{array}$ & $\begin{array}{c}\text { 1 Minggu } \\
\mathrm{q}_{\mathrm{u}}\left(\mathrm{kN} / \mathrm{m}^{2}\right)\end{array}$ & $\begin{array}{c}\text { 3 Minggu } \\
\mathrm{q}_{\mathrm{u}}\left(\mathrm{kN} / \mathrm{m}^{2}\right)\end{array}$ & $\begin{array}{c}5 \text { Minggu } \\
\mathrm{q}_{\mathrm{u}}\left(\mathrm{kN} / \mathrm{m}^{2}\right)\end{array}$ & $\begin{array}{c}7 \text { Minggu } \\
\mathrm{q}_{\mathrm{u}}\left(\mathrm{kN} / \mathrm{m}^{2}\right)\end{array}$ \\
\hline Sampel 1 & 11.81 & 9.58 & 9.65 & - \\
\hline Sampel 2 & 11.46 & 9.34 & 9.36 & - \\
\hline Sampel 3 & - & 9.39 & 9.13 & 9.45 \\
\hline Sampel 4 & - & 9.37 & 9.34 & - \\
\hline Avg & 11.635 & 9.42 & 9.37 & 9.45 \\
\hline
\end{tabular}




\section{Hasil Perhitungan Nilai Kohesi}

Setelah memperoleh nilai kuat tekan tiap sampel, kita dapat memperoleh nilai kohesi dari rumus empiris. Untuk nilai kohesi sampel tidak rendam akan disajikan dalam Tabel 7 dan untuk nilai kohesi sampel rendam akan disajikan dalam Tabel 8.

Tabel 7. Nilai Kohesi Sampel Tidak Rendam

\begin{tabular}{|c|c|c|c|c|c|}
\hline Sampel & 0 Minggu & 1 Minggu & 3 Minggu & 5 Minggu & 7 Minggu \\
\hline UCT & $\mathrm{C}\left(\mathrm{kN} / \mathrm{m}^{2}\right)$ & $\mathrm{C}\left(\mathrm{kN} / \mathrm{m}^{2}\right)$ & $\mathrm{C}\left(\mathrm{kN} / \mathrm{m}^{2}\right)$ & $\mathrm{C}\left(\mathrm{kN} / \mathrm{m}^{2}\right)$ & $\mathrm{C}\left(\mathrm{kN} / \mathrm{m}^{2}\right)$ \\
\hline Sampel 1 & 156.04 & 316.95 & 576.31 & 596.93 & 582.065 \\
\hline Sampel 2 & 132.875 & 253.475 & 272.445 & 596.3 & 467.535 \\
\hline Sampel 3 & - & - & - & 476.45 & 449.22 \\
\hline Sampel 4 & - & - & - & 596.775 & 496.59 \\
\hline Avg & 144.4575 & 285.2125 & 424.3775 & 566.61375 & 498.8525 \\
\hline
\end{tabular}

Tabel 8. Nilai Kohesi Sampel Rendam

\begin{tabular}{ccccc}
\hline $\begin{array}{c}\text { Sampel } \\
\text { UCT }\end{array}$ & $\begin{array}{c}\text { 1 Minggu } \\
\mathrm{C}\left(\mathrm{kN} / \mathrm{m}^{2}\right)\end{array}$ & $\begin{array}{c}\text { 3 Minggu } \\
\mathrm{C}\left(\mathrm{kN} / \mathrm{m}^{2}\right)\end{array}$ & $\begin{array}{c}\text { C }\left(\mathrm{kN} / \mathrm{m}^{2}\right) \\
\mathrm{C}\left(\mathrm{kN} / \mathrm{m}^{2}\right)\end{array}$ \\
\hline Sampel 1 & 5.905 & 4.79 & 4.825 & - \\
\hline Sampel 2 & 5.73 & 4.67 & 4.68 & - \\
\hline Sampel 3 & - & 4.695 & 4.565 & 4.725 \\
\hline Sampel 4 & - & 4.685 & 4.67 & - \\
\hline Avg & 5.8175 & 4.71 & 4.685 & 4.725 \\
\hline
\end{tabular}

\section{Hasil Perhitungan Nilai Sudut Geser Dalam}

Berdasarkan nilai kohesi yang diperoleh, kita dapat menentukan besaran nilai sudut geser dalam tiap sampel dengan menggunakan korelasi antara nilai kohesi terhadap nilai N-SPT. Setelah memperoleh nilai N-SPT maka akan digunakan interpolasi linear untuk mencari nilai sudut geser dalam. Untuk nilai sudut geser dalam sampel tidak rendam akan disajikan dalam Tabel 9 dan untuk sampel rendam akan disajikan dalam Tabel 10.

Tabel 9. Hasil Perhitungan Nilasi Sudut Geser Dalam Sampel Tidak Rendam

\begin{tabular}{|c|c|c|c|c|c|c|}
\hline Week & Sampel & $\mathrm{Su} / \mathrm{C}\left(\mathrm{kN} / \mathrm{m}^{2}\right)$ & $\mathrm{Su} / \mathrm{C}\left(\mathrm{kg} / \mathrm{cm}^{2}\right)$ & $\mathrm{Su} / \mathrm{C}$ (tsf) & $\begin{array}{c}\text { N-SPT } \\
\mathrm{Su}=0.038 \mathrm{~N}\end{array}$ & $\varnothing\left(^{\circ}\right)$ \\
\hline \multirow{3}{*}{0} & 1 & 156.040 & 1.591 & 1.740 & 45.796 & 43.949 \\
\hline & 2 & 132.875 & 1.355 & 1.482 & 38.998 & 42.249 \\
\hline & Avg & 144.458 & 1.473 & 1.611 & 42.397 & 43.099 \\
\hline \multirow{3}{*}{1} & 1 & 316.950 & 3.232 & 3.535 & 93.022 & 55.755 \\
\hline & 2 & 253.475 & 2.585 & 2.827 & 74.392 & 51.098 \\
\hline & Avg & 285.213 & 2.908 & 3.181 & 83.707 & 53.427 \\
\hline 3 & 1 & 576.310 & 5.877 & 6.427 & 169.141 & 74.785 \\
\hline
\end{tabular}




\begin{tabular}{|c|c|c|c|c|c|c|}
\hline & 2 & 272.445 & 2.778 & 3.038 & 79.960 & 52.490 \\
\hline & Avg & 424.378 & 4.327 & 4.733 & 124.551 & 63.638 \\
\hline \multirow{5}{*}{5} & 1 & 596.930 & 6.087 & 6.657 & 175.193 & 76.298 \\
\hline & 2 & 596.300 & 6.081 & 6.650 & 175.008 & 76.252 \\
\hline & 3 & 476.450 & 4.858 & 5.314 & 139.834 & 67.458 \\
\hline & 4 & 596.775 & 6.085 & 6.656 & 175.148 & 76.287 \\
\hline & Avg & 566.614 & 5.778 & 6.319 & 166.296 & 74.074 \\
\hline \multirow{5}{*}{7} & 1 & 582.065 & 5.935 & 6.492 & 170.831 & 75.208 \\
\hline & 2 & 467.535 & 4.768 & 5.214 & 137.217 & 66.804 \\
\hline & 3 & 449.220 & 4.581 & 5.010 & 131.842 & 65.460 \\
\hline & 4 & 496.590 & 5.064 & 5.538 & 145.744 & 68.936 \\
\hline & Avg & 498.853 & 5.087 & 5.564 & 146.408 & 69.102 \\
\hline
\end{tabular}

Tabel 10. Hasil Perhitungan Nilasi Sudut Geser Dalam Sampel Rendam

\begin{tabular}{|c|c|c|c|c|c|c|}
\hline Week & Sampel & $\mathrm{Su} / \mathrm{C}\left(\mathrm{kN} / \mathrm{m}^{2}\right)$ & $\mathrm{Su} / \mathrm{C}\left(\mathrm{kg} / \mathrm{cm}^{2}\right)$ & $\mathrm{Su} / \mathrm{C}$ (tsf) & $\begin{array}{c}\text { N-SPT } \\
\mathrm{Su}=0.038 \mathrm{~N}\end{array}$ & $\varnothing\left({ }^{\circ}\right)$ \\
\hline \multirow{5}{*}{1} & 1 & 5.905 & 0.060 & 0.066 & 1.733 & 12.998 \\
\hline & 2 & 5.730 & 0.058 & 0.064 & 1.682 & 12.613 \\
\hline & 3 & 4.625 & 0.047 & 0.052 & 1.357 & 10.180 \\
\hline & 4 & 1.910 & 0.019 & 0.021 & 0.561 & 4.204 \\
\hline & Avg & 4.543 & 0.046 & 0.051 & 1.333 & 9.999 \\
\hline \multirow{5}{*}{3} & 1 & 4.790 & 0.049 & 0.053 & 1.406 & 10.544 \\
\hline & 2 & 4.670 & 0.048 & 0.052 & 1.371 & 10.280 \\
\hline & 3 & 4.695 & 0.048 & 0.052 & 1.378 & 10.335 \\
\hline & 4 & 4.685 & 0.048 & 0.052 & 1.375 & 10.313 \\
\hline & Avg & 4.710 & 0.048 & 0.053 & 1.382 & 10.368 \\
\hline \multirow{5}{*}{5} & 1 & 4.825 & 0.049 & 0.054 & 1.416 & 10.621 \\
\hline & 2 & 4.680 & 0.048 & 0.052 & 1.374 & 10.302 \\
\hline & 3 & 4.565 & 0.047 & 0.051 & 1.340 & 10.048 \\
\hline & 4 & 4.670 & 0.048 & 0.052 & 1.371 & 10.280 \\
\hline & Avg & 4.685 & 0.048 & 0.052 & 1.375 & 10.313 \\
\hline \multirow{5}{*}{7} & 1 & 7.710 & 0.079 & 0.086 & 2.263 & 16.971 \\
\hline & 2 & 6.105 & 0.062 & 0.068 & 1.792 & 13.438 \\
\hline & 3 & 4.725 & 0.048 & 0.053 & 1.387 & 10.401 \\
\hline & 4 & 6.110 & 0.062 & 0.068 & 1.793 & 13.449 \\
\hline & Avg & 6.163 & 0.063 & 0.069 & 1.809 & 13.565 \\
\hline
\end{tabular}




\section{Perbandingan Nilai Kuat Tekan dan Nilai Kohesi Sampel Tidak Rendam dan Sampel Rendam}

Nilai kuat tekan dan nilai kohesi pada percobaan UCT dapat dikatakan berbanding lurus dikarenakan nilai kuat tekan hanya dibagi dua maka akan diperoleh nilai kohesi. Untuk persentase perbedaan nilai kuat tekan dan kohesi terbesar pada percobaan ini berada pada kondisi sampel 5 minggu sebesar 99.173\%. Grafik perbandingan nilai kuat tekan akan disajikan dalam Gambar 3 dan untuk grafik perbandingan kohesi akan disajikan dalam Gambar 4.

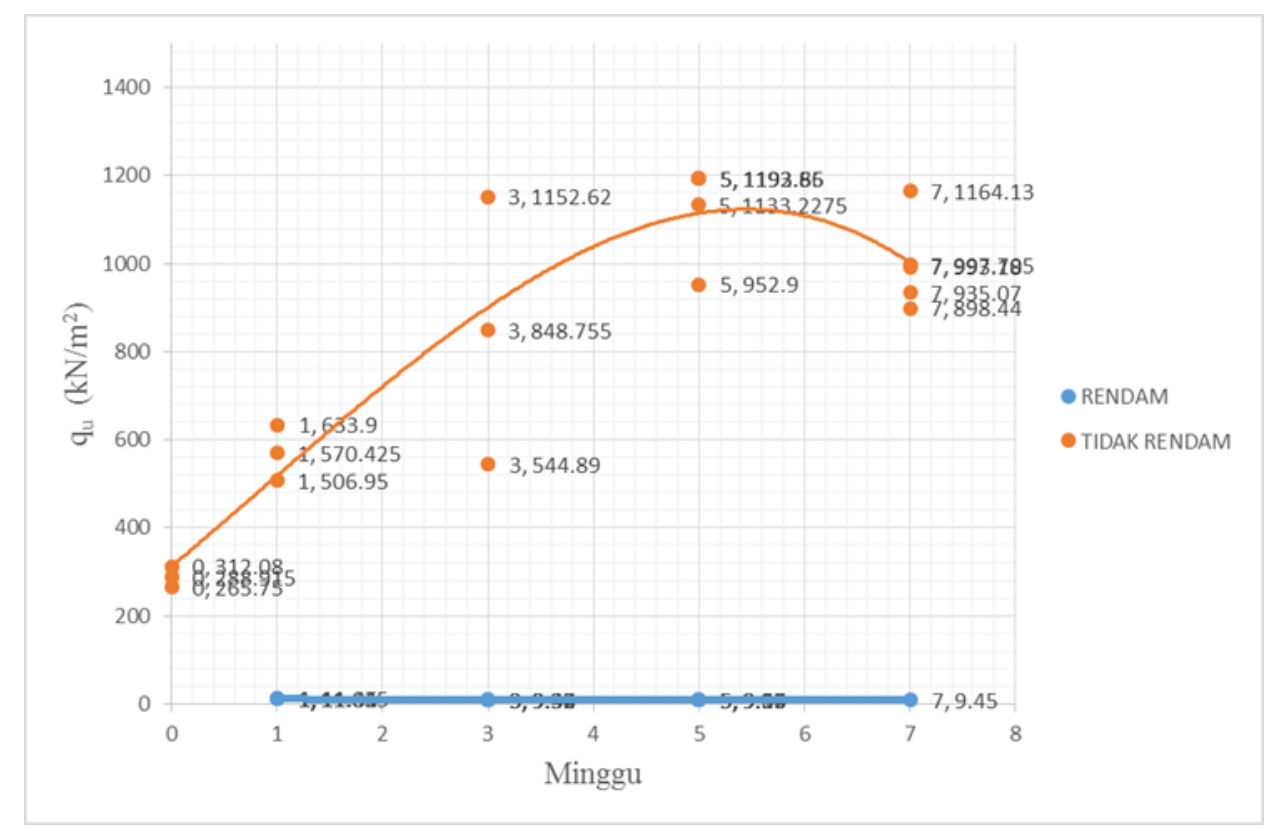

Gambar 3. Perbandingan Nilai Kuat Tekan Sampel Tidak Rendam dan Sampel Rendam

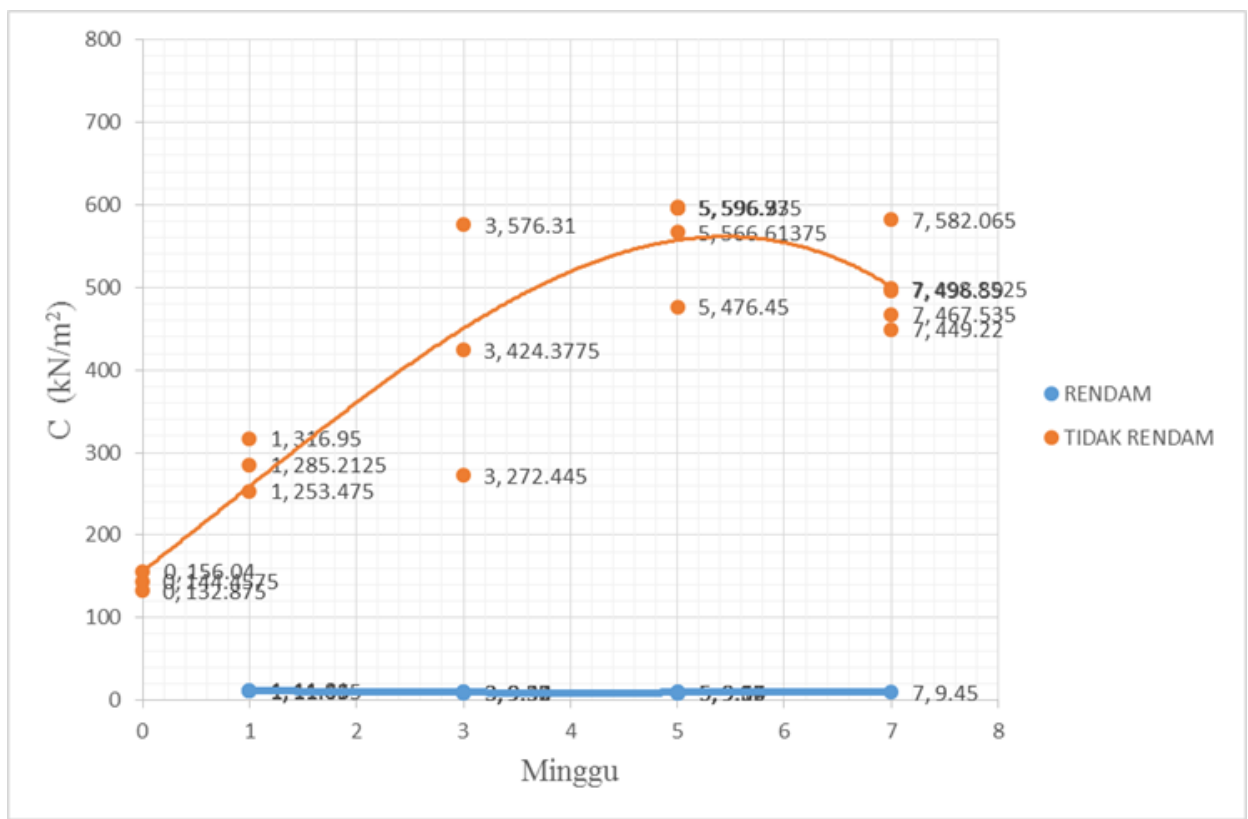

Gambar 4. Perbandingan Nilai Kohesi Sampel Tidak Rendam dan Sampel Rendam 


\section{KESIMPULAN}

Berdasarkan Gambar 3 dan Gambar 4, diketahui bahwa nilai kuat tekan dan kohesi terbesar untuk sampel tidak rendam berada pada sampel kondisi pendiaman selama 5 minggu dan akan menurun ketika sampel memasuki pendiaman selama 7 minggu.

Berdasarkan Gambar 3 dan Gambar 4, diketahui bahwa nilai kuat tekan dan kohesi terbesar untuk sampel rendam berada pada sampel kondisi perendaman selama 1 minggu dan akan menurun ketika sampel memasuki perendaman selama 3 minggu.

Persen perbedaan nilai kuat tekan dan kohesi terbesar antara sampel tidak rendam dan sampel rendam berada pada sampel dengan durasi 5 minggu sebesar $99.173 \%$.

\section{DAFTAR PUSTAKA}

ASTM D-2116. 2014. Standard Test Method for Unconfined Compressive Strength of Cohesive Soil. United States: American Society for Testing and Materials.

Anggour, S. M. 2002. Updating Bearing Capacity - SPT Graphs. Maryland: Civil and Environmental Engineering Department. University of Maryland

Meyerhof, G.G. 1956. Penetration test and bearing capacity of cohesionless soils. Journal of the Soil Mechanics and Foundtaion Division, 82(1), 1-19 
